\title{
Design, Development, Test, and Evaluation of Atmosphere Revitalization and Environmental Monitoring Systems for Long Duration Missions
}

\author{
Monsi C. Roman ${ }^{1}$ and Jay L. Perry ${ }^{2}$ \\ NASA/Marshall Space Flight Center, Huntsville, AL 35812 \\ Darrell L. $\mathrm{Jan}^{3}$ \\ NASA/Jet Propulsion Laboratory, Pasadena, CA 91109
}

\begin{abstract}
The Advanced Exploration Systems Program's Atmosphere Resource Recovery and Environmental Monitoring (ARREM) project is working to mature optimum atmosphere revitalization and environmental monitoring system architectures. It is the project's objective to enable exploration beyond Lower Earth Orbit (LEO) and improve affordability by focusing on three primary goals: 1) achieving high reliability, 2) reducing dependence on a ground-based logistics resupply model, and 3) maximizing commonality between atmosphere revitalization subsystem components and those needed to support other exploration elements. The ARREM project's strengths include using existing developmental hardware and testing facilities, when possible, and and a well-coordinated effort among the NASA field centers that contributed to past ARS and EMS technology development projects.
\end{abstract}

\section{Nomenclature}

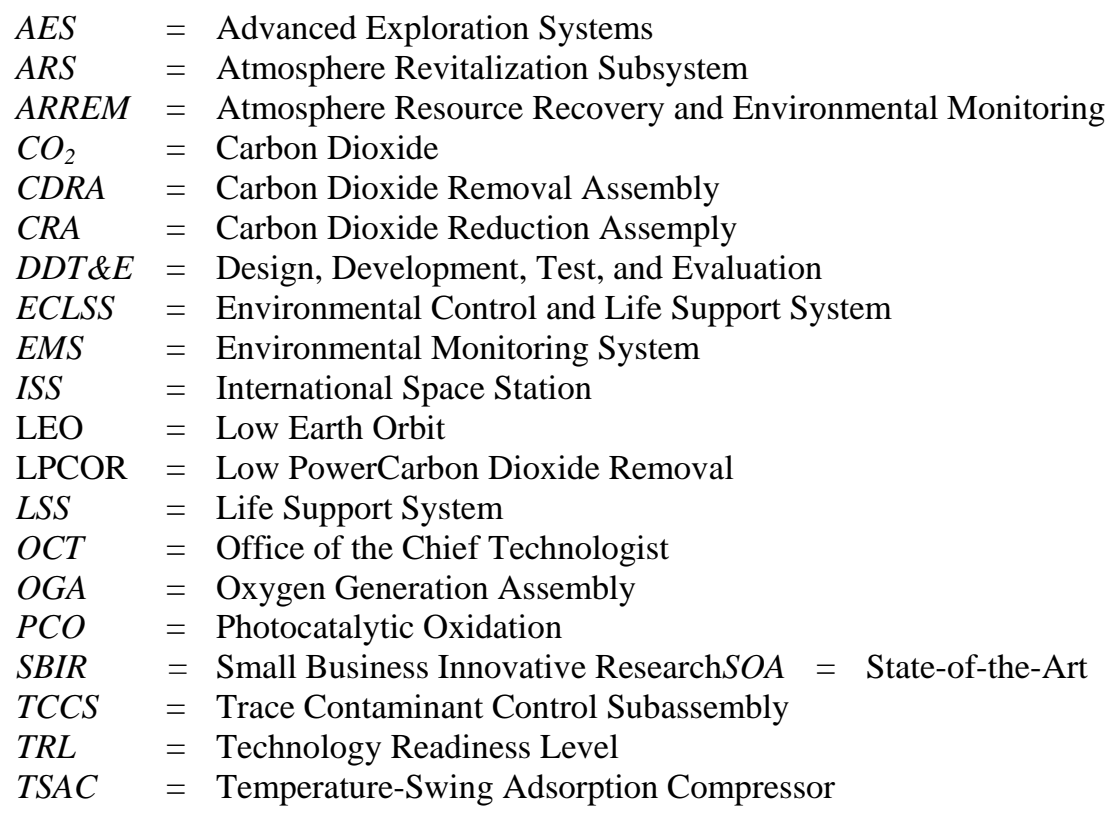

\section{Introduction}

—UTURE crewed long duration space missions will need to maintain conditions for human habitability, just has 1 the International Space Station (ISS) has done for over a decade. Although the next space exploration destination for crewed vehicles is still somewhat uncertain, there are some important differences from the ISS experience-lack of proximity to Earth will cause a ground-based logistics resupply model to become impractical,

\footnotetext{
${ }^{1}$ Project Manager/Scientist, Science and Technology Office/ZP31, NASA/MSFC, Huntsville, AL 35812.

${ }^{2}$ Engineer, Environmental Control Systems, Space Systems Dept./ES62, NASA/MSFC, Huntsville, AL 35812.

${ }^{3}$ Manager, Human/Robotic Mission Systems Office, Dept. 4720/MS 301-420, NASA JPL, Pasadena, CA 91109.
} 
limitations for delivering mass to the destination will require a smaller habitable platform with accompanying equipment mass and volume constraints that are more challenging than ISS, hence all associated hardware will be more volume and mass constrained, making reliable closed-loop life support an important objective, and the breadth of possible exploration destinations is wide requiring a highly flexible overall approach that can accommodate a range of mission designs.

The deep space exploration missions of the future must be affordable; therefore, it is vital to minimize destination-specific technical development. For life support systems (LSS), this means that there is the need for functional flexibility to enable a safe, affordable, and sustainable human presence in space regardless of the mission destination or habitable platform. An approach to strategically achieve this needed flexibility employs a common core life support equipment architecture with modularity as a key system and equipment design feature at the lowest functional level possible. Doing so provides tangible non-recurring and recurring cost reduction through using a common design, development, test, and evaluation (DDT\&E) and sustaining infrastructure program to accommodate varied exploration objectives and habitable platforms. Exploration risk will also be reduced by the accumulation of operational experience with modular and common systems as the exploration framework is incrementally executed.

At the end of the U.S. government fiscal year 2011 (GFY11), NASA Environmental Control and Life Support Systems (ECLSS) experts responded to the Advanced Exploration Systems (AES) Program's request for a series of proposals to address the LSS needs for long duration missions beyond low Earth orbit (LEO). The Atmosphere Resource Recovery and Environmental Monitoring (ARREM) project was selected for implementation in GFY12 as part of a group of LSS-related projects that were commissioned to develop the architectural concepts needed to support future deep space exploration missions. The ARREM Project, managed by Marshall Space Flight Center and supported by four participating NASA field centers, is supported by the AES Program within NASA's Human Exploration and Operations Mission Directorate (HEOMD).

The following discussion summarizes NASA's ARREM project plans and objectives for developing and demonstrating process technologies and architectures for Atmosphere Revitalization Subsystems (ARS) and Environmental Monitoring Subsystems (EMS) that will meet the technical demands of future crewed missions beyond LEO.

\section{Background}

The benefits of adopting an overall highly flexible, modular architectural approach early in LSS system development can be illustrated by considering the technology development directions that were being pursued for the carbon dioxide $\left(\mathrm{CO}_{2}\right)$ control function during the Constellation Program.

\section{A. A Drive Toward Multi-Platform Commonality}

Orion, the first crewed element to enter into development, adopted an amine-based, pressure-swing regenerable bed to adsorb both $\left(\mathrm{CO}_{2}\right)$ and humidity from the cabin and vent it overboard. Lunar lander studies indicated that the $\mathrm{CO}_{2}$ removal technology under development for the Orion Project would likely meet its mission needs but that some degree of resizing might have been in order. A corresponding development for the extravehicular activity (EVA) portable life support system (PLSS) design also included an amine-based pressure-swing regenerable $\mathrm{CO}_{2}$ removal component, but the small volume of the suit and packaging constraints within the PLSS drove that equipment design concept towards unique sizing and operating cycles.

Lunar surface exploration using a pressurized rover would be relatively short in duration and likely would have been supportable with Orion-like or PLSS-like $\mathrm{CO}_{2}$ removal process technology except that the large number of excursions envisioned over an entire lunar campaign would have led to substantial consumable losses - both water and $\mathrm{CO}_{2}$. The pressurized rover therefore adopted a "water save" approach on the front end of swing beds to capture cabin humidity condensate for eventual return to an outpost element for reclamation. Other pressurized rover studies considered the feasibility of utilizing PLSS swing beds in a variety of configurations. Those studies suggested that such an approach appeared feasible but would require more detailed analysis and testing to prove.

Lunar outpost habitats, dedicated to meeting the long duration demands of lunar surface campaigns, were envisioned to be the centers in which resource recovery capabilities would be located. To enable oxygen $\left(\mathrm{O}_{2}\right)$ recovery, habitat $\mathrm{CO}_{2}$ removal technologies were envisioned to be zeolite-based due to the comparatively more energy-efficient temperature-swing adsorption (TSA) process compared to the amine-based pressure-swing regeneration process which required a large vacuum pump. The amine cannot be heated due to substrate thermal stability and amine volatility issues while pellitized zeolites are thermally stable. Long-term concerns also existed for amine-based pressure-swing regenerable processes due to the amine sorbent's ammonia $\left(\mathrm{NH}_{3}\right)$ offgassing characteristics that place an added load on the trace contaminant control equipment. As a result, the Constellation 
Project was headed in a direction of having a minimum of three and as many as five different design solutions for performing the $\mathrm{CO}_{2}$ removal function, most of which were difficult and inefficient for optimizing for resource recovery.

\section{B. A Function-Based, Flexible Framework}

By re-examining the exploration framework as an integrated whole consisting of key functional trade spaces, opportunities were identified for using common core LSS process technologies and equipment in a modular "building block" fashion across a wide range of exploration mission concepts. ${ }^{1}$ The ARREM Project is designed to acquire data and lessons learned that will be useful for guiding exploration mission technology maturation and establishing a technical foundation upon which exploration partnerships and contract strategies can be formulated, all targeted to the eventual development of a core LSS system infrastructure that can be widely applied throughout the exploration architecture.

\section{Technical Objectives}

The ARREM Project's primary objectives are to mature integrated ARS and EMS concepts that will reduce risk, lower lifecycle cost, and validate operational process design and system architectural concepts for future crewed space exploration missions beyond LEO. The goals of the ARS and EMS technology maturation tasks within the ARREM Project are the following:

1) To assess existing ARS and EMS candidates that offer the greatest potential to maximize system commonality across a variety of mission scenarios and vehicle concepts anticipated in a flexible exploration framework.

2) To advance the technical maturity as measured by the Technology Readiness Level (TRL) of candidate technologies for flexible ARS architectures spanning the range of exploration mission objectives and vehicle concepts thus providing risk reduction and developmental economy to flight project development programs.

3) To develop a set of resource recovery capabilities that can be added in modular fashion to a modular common core ARS process architecture to allow mission planners flexibility to extend crewed mission durations without compromising core equipment functionality.

4) To demonstrate the evolution of the ISS SOA ARS/EMS via targeted advancements that benefit ISS operations in LEO and exploration missions beyond Earth orbit. Benefits include improved operational margins and reliability, reduced technical risk, and lower lifecycle cost.

The ARREM Project focuses on key physico-chemical process technologies for ARS that increase reliability, capability, and consumable mass recovery as well as reduce requirements for power, volume, heat rejection, and crew involvement.

In support of the EMS task, the project objectives are to develop and demonstrate onboard analytical capabilities which will replace the need to return air and water samples to earth for ground-based laboratory analysis. This effort addresses these challenges by adopting a new architecture that is based on a modular integration of multiple sensing modalities, employing a hybrid combination of simple, rugged, technologies and, where needed, highly capable complex approaches, to completely address monitoring needs of the future. The architecture incorporates microelectromechanical system (MEMS) technologies to enable significant miniaturization over current systems, and selects elements offering both low resources and high reliability operation for affordability. Previous NASA development results as well as emerging commercial and academic accomplishments are leveraged to achieve these ends.

The ARREM Project will develop, demonstrate and/or test leading process technology candidates and subsystem architectures that will meet or exceed current requirements and fill capability gaps or significantly improve the efficiency, safety, and reliability over the ISS State-of-Art (SOA). The project's main goal will be to demonstrate ARS and EMS components and subsystem architectures in ground-based facilities. The best-suited testing/demonstration methods, facilities, and level of integration for each candidate process technology and/or integrated system architecture are assessed based on priorities, availability, needs and resources.

\section{Technical Approach}

Examining the exploration framework as an integrated whole, opportunities have been identified for demonstrating the concept of common core ARS and EMS technologies and equipment in a modular "building block" fashion across a range of crewed mission designs lasting up to one year duration or longer. It is expected that the ARREM Project will generate technical products including but not limited to test results and lessons learned that 
will be useful in guiding follow-on technology maturation and in establishing a technical foundation upon which exploration partnerships and contract strategies can be formulated, all targeted to the eventual development of a core ARS and EMS infrastructure that can be widely applied throughout the exploration architecture and demonstrated to be readily integrated with equipment that efficiently recovers valuable resources to vastly simplify long duration exploration mission logistics support. ${ }^{2}$

Existing developmental test equipment providing the core ARS functions was chosen for the initial ARREM project testing basis shown by Fig. 1. The assortment of test equipment includes the following:

1) ISS developmental test articles

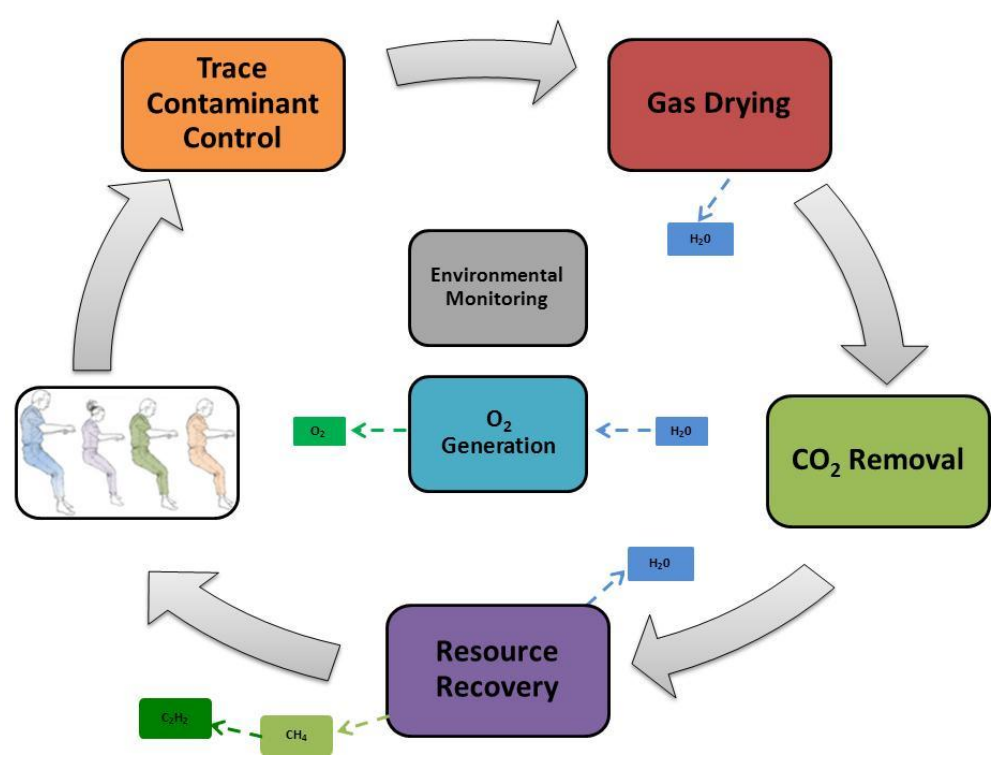

Figure 1. The ARS and EMS functional integration concept.

2) Developmental test articles from the former NASA Exploration Technology Development Project (ETDP)

3) Equipment deliverables from Small Business Innovative Research (SBIR) contracts

4) Equipment developed under the NASA Office of the Chief Technologist (OCT) projects

The test equipment is integrated and tested, in appropriate combinations, under conditions selected to encompass anticipated exploration habitable platform cabin atmospheres and loads.

Consistent with a flexible crewed space exploration strategy, the ARREM Project will demonstrate the capability to extend the functional utility of a common set of core ARS and EMS equipment by integrating them with reliable, cost-effective resource recovery capabilities that will allow long-duration human exploration missions to be sustained with minimal dependence on earth-based logistics support. The basis for the development will be SOA ARS equipment already operational in the ISS, as well as the products of other programs/projects within NASA and outside of NASA. This provides the project a basis for comparison for improvements that could involve enhancements and/or replacements. Supplemental equipment for accomplishing resource recovery will be sized, integrated, and operated along with core ARS equipment to demonstrate the capability to perform reliable, efficient resource recovery without compromising the reliability or performance of core functions and demonstrating seamless application of the core ARS equipment architecture as the central component of a total integrated system capable of resource recovery.

Candidate resource recovery functions include capabilities to recover latent water (humidity) collected from cabin atmospheres for eventual purification into potable water as well as capabilities to recover $\mathrm{O}_{2}$ from metabolic $\mathrm{CO}_{2}$. Such resource recovery capabilities can provide substantial mission life cycle savings not just in deep space habitats but also potentially in smaller vehicles such as Multi-Mission Space Exploration Vehicles (MMSEVs) and pressurized surface rovers that might find repeated use over an extended exploration campaign.The ARREM project partnered with the ISS program to support chamber-based testing activities being performed on behalf of the ISS program which includes the integration of developmental test articles representing the current ISS SOA ARS functions. Test articles include a Carbon Dioxide Removal Assembly (CDRA), Oxygen Generation Assembly (OGA), Sabatier-based $\mathrm{CO}_{2}$ Reduction Assembly (CRA), and Trace Contaminant Control Subassembly (TCCS). The integrated testing will provide detailed ground-based performance data, including the fate of environmental contaminants as they enter and potentially pass through the CDRA and into the high temperature CRA reactor. Although this testing directly supports the ISS program, it also sets a performance basis for comparison for alternative process technologies performing core environmental control functions. The integrated test setup also provides an integrated platform within which to demonstrate alternative technologies and component configurations in an orderly fashion under a variety of conditions. 
The ARREM Project's Environmental Monitoring Task, summarized by Fig. 2, focuses on the integration of airborne chemical monitors developed for spacecraft applications as well as microbial monitoring technologies. The selection will be based on the technologies that can meet the needed assessments of the LSS and their compatibility with exploration mission demands. ${ }^{3}$

Existing LSS test articles, shown by Fig. 3, that build from ISS Program developmental equipment will serve as the starting basis. Equipment and components incorporating alternative process technologies considered as worthy candidates suited for advancing core functional capabilities beyond the current ISS SOA will be incorporated into the testing architecture to the maximum extent possible. Because these test articles will come from various sources and will have achieved varying degrees of maturity, they will not be precisely matched with regard to size, interfaces and operating characteristics, and performance levels. Despite this reality, it is still anticipated that valid integrated test and evaluation results can be achieved with only modest hardware adaptations.

The ARS and EMS equipment will be integrated within the Exploration Chamber (E-Chamber) at MSFC, shown by Fig. 4., and tested using combinations of pressure, $\mathrm{O}_{2}$ partial pressure, $\mathrm{CO}_{2}$ partial pressure, and humidity that are representative of a range of anticipated cabin atmospheric conditions and loads.

Test articles include a Carbon Dioxide Removal Assembly (CDRA), Sabatier Carbon Dioxide Reduction Assembly (CRA), Oxygen Generation Assembly (OGA) and Trace Contaminant Control Subsystem (TCCS). Initial testing uses the equipment arranged in the ISS ARS architecture to provide detailed groundbased performance data, including further insight on the fate of environmental contaminants as they enter and potentially pass through the CDRA and into the high temperature CRA reactor. Although this testing

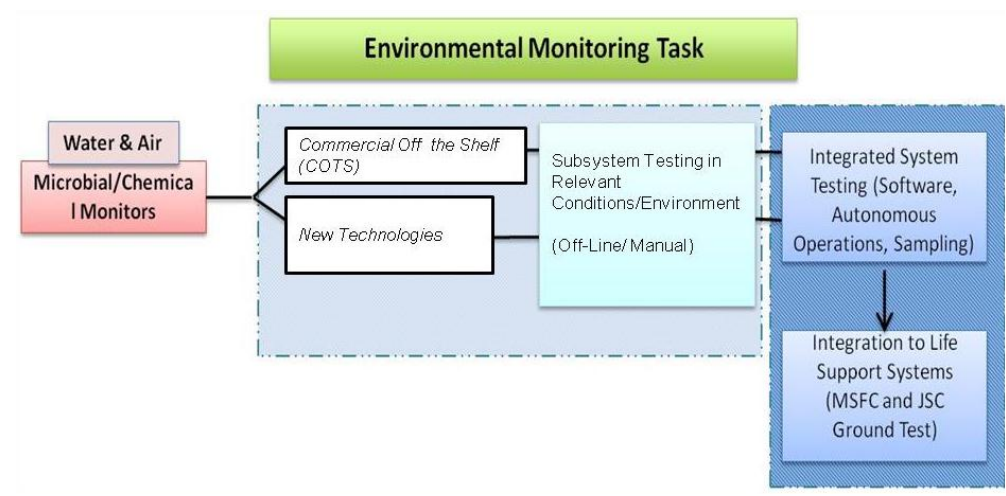

Figure 2. The ARREM Project environmental monitoring task.

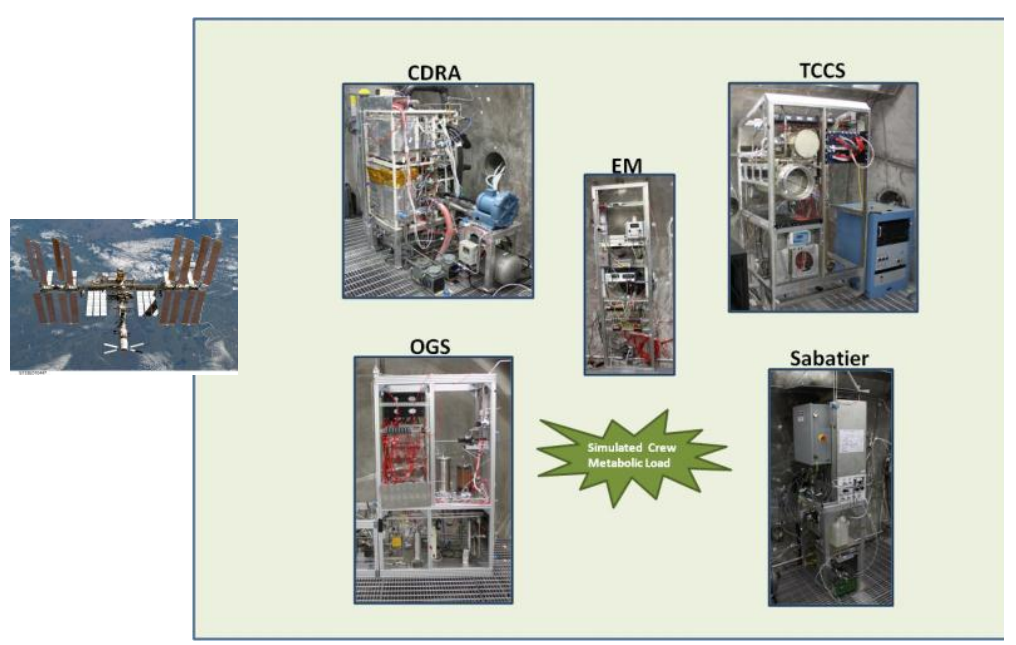

Figure 3. ISS Program developmental equipment. Existing groundbased testing equipment will be modified to achieve project objectives.

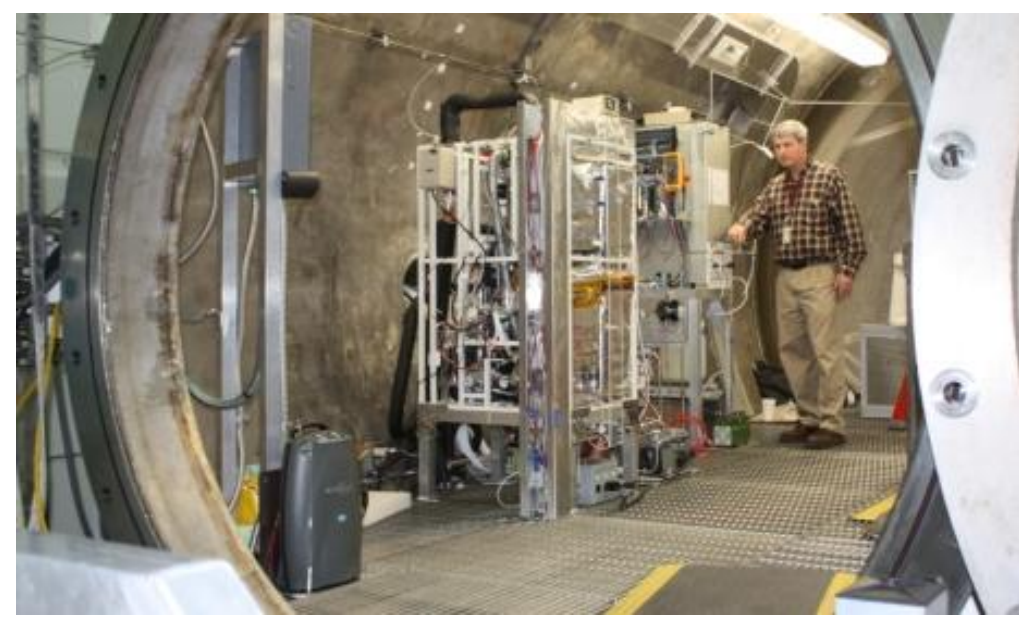

Figure 4. E-Chamber for integrated ARS and EMS testing. Functional demonstration will be accomplished via a three-level testing protocol. 
directly supports the ISS Program, it also establishes a basis for comparison against which alternative technologies under evaluation by the ARREM Project can be compared.

The E-Chamber test setup provides an integrated platform within which alternative technologies and component configurations will be installed in an evolutionary manner to understand how they may improve the ISS ARS and EMS functions. The most mature candidate process technologies will be tested and evaluated against the corresponding ISS SOA functions. A number of process technology candidates have been selected for evaluation.

\section{Project Organization}

To properly address the challenges of each LSS functional area, a multi-disciplinary team of subject matter experts will conduct focused technology development work with complementary support provided by experts located within NASA, other government agencies, federal laboratories, academia, and industry. Technology maturation will be conducted for resource recovery, particulate filtration, trace chemical contaminant removal, humidity removal and recovery, and $\mathrm{CO}_{2}$ removal. Environmental monitoring equipment concepts will be provided to be responsive to needs based directly on crew health as well as LSS monitoring and process control.

Technical tasks that comprise the ARREM Project address LSS core functional areas summarized by Fig. 5 . Tasks are broad-based and diverse, but all carry the common goal of identifying and maturing advanced life support process technologies that build from the ISS architecture and equipment characteristics to achieve greater reliability and are also capable of enduring the natural environments encountered by their host spacecraft for long duration missions beyond LEO. The functional areas to be developed orenhanced through testing and analyses by the ARREM Project are described by the following summary.
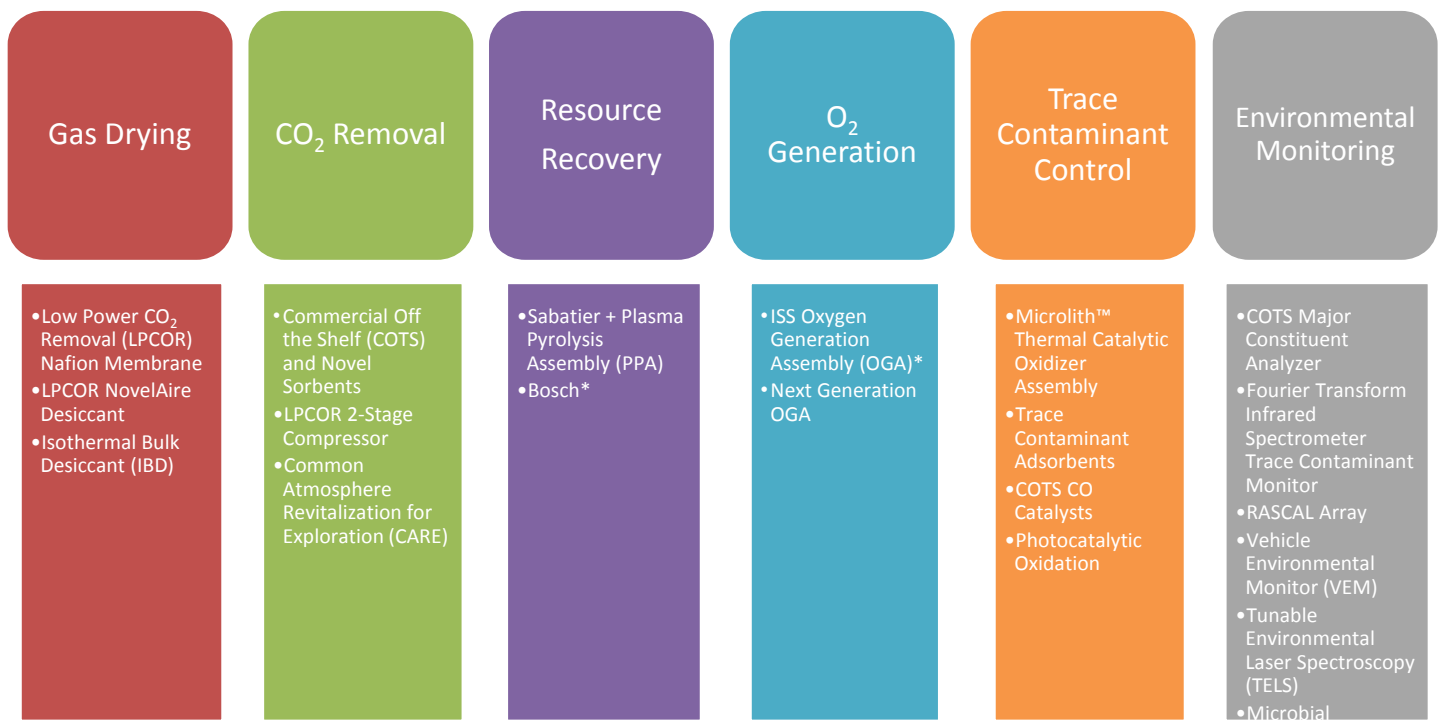

Figure 5. ARREM Project functional development areas.

\section{A. Carbon Dioxide Removal and Gas Drying}

Building on the ISS Carbon Dioxide Removal Assembly (CDRA) process architecture, this task applies improved, more durable $\mathrm{CO}_{2}$ sorbents to firstly improve the reliability of the CDRA process. Open loop $\mathrm{CO}_{2}$ removal concepts that use either immobilized amine or mixed zeolite sorbents that can potentially replace the $\mathrm{CO}_{2}$ removal beds in a CDRA-like process architecture will be evaluated. Likewise, energy-efficient structured sorbents and other alternative sorbents as well as membrane processes derived from the low power $\mathrm{CO}_{2}$ removal process development will be investigated for both process air drying and $\mathrm{CO}_{2}$ removal. The best performing options will be considered for CDRA component retrofit and/or CDRA equipment replacement. Cabin and ventilation system interface issues, including interface issues with a vehicle suit loop will be investigated. Areas for technical emphasis for the $\mathrm{CO}_{2}$ removal function are the following:

1) Amine-based open loop $\mathrm{CO}_{2}$ removal

2) Zeolite-based physical adsorbents for $\mathrm{CO}_{2}$ removal

3) Process air drying techniques using membranes and structure adsorbent media

4) $\mathrm{CO}_{2}$ compression and storage approaches

5) Common $\mathrm{CO}_{2}$ removal component designs 


\section{B. Resource Recovery and Oxygen Generation}

Building on the ISS Oxygen Generation Assembly (OGA) equipment platform, this task will develop a more robust, reliable water electrolysis cell stack that addresses observed ISS reliability issues. Oxygen drying and compression options, both temperature swing adsorption-based and mechanical compressor-based, will be considered. Plasma methane pyrolysis, the leading methods for recovering additional hydrogen from the ISS Sabatier process waste methane will be evaluated. Methods for handling hydrogen $\left(\mathrm{H}_{2}\right)$ and acetylene $\left(\mathrm{C}_{2} \mathrm{H}_{2}\right)$ within the OGA-Sabatier-methane post-processing string will be investigated. Specific technical areas of emphasis for resource recovery are the following:

1) Sabatier-based $\mathrm{CO}_{2}$ reduction

2) Methane Pyrolysis

3) Proton Exchange Membrane (PEM) $\mathrm{H}_{2} \mathrm{O}$ Electrolysis

4) Gas Handling and Management $\left(\mathrm{CO}_{2}, \mathrm{H}_{2}, \mathrm{C}_{2} \mathrm{H}_{2}, \& \mathrm{O}_{2}\right.$ compression \& separations)

\section{Trace Contaminant Control}

The best performing adsorbent media and catalysts will be applied to an ISS-derived trace contaminant control (TCC) process design. Commercially available and developmental particulate filtration media and indexing media filter concepts will be applied to improve the performance of the ISS particulate filtration architecture. Based on system architecture trade assessment, options for integrating TCC and particulate matter control equipment with $\mathrm{CO}_{2}$ removal equipment to achieve a common core atmosphere revitalization architecture for deep space exploration missions will be investigated and demonstrated. Options for applying advanced TCC adsorbents and catalysts to the ISS TCC equipment to further improve operational robustness will be considered and communicated to the ISS Program. Further development of photocatalytic oxidation processes to niche applications that reduce volatile organic loading in humidity condensate will be conducted to alleviate the logistics penalty associated with this phenomenon as observed aboard the ISS. The project will evaluate various commercial and developmental filters in the Particulate Filtration Testing Facility. Also, a scale-up version of the Indexing Media Filter system to full scale $(100 \mathrm{cfm})$ or other relevant size and format (mission relevant) will be developed.Specific areas of emphasis for TCC are the following:

1) Commercial adsorbents and catalyst characterization

2) Photocatalytic oxidation

3) Microlith $^{\mathrm{TM}}$ thermal catalytic oxidation

4) Microlith ${ }^{\mathrm{TM}}$ engineered structured sorbent

5) Commercial and developmental filtration media characterization

6) Indexing media filter system

\section{Environmental Monitoring}

The available performing atmospheric monitoring candidates demonstrated on board the ISS to date will be operated in tandem to help determine the optimal suite of instruments necessary to provide vehicle operational autonomy necessary for deep exploration missions. Monitoring instrument recommendations will be submitted to the ISS Program to improve functional autonomy and reduce reliance on assessing cabin air quality using grab samples that rely on ground analysis and logistics between Earth and orbit. Early warning instruments targeting specific analytical targets will be demonstrated. Extending air quality instrument function to include front-end processors to allow for volatile organic monitoring in potable water will be demonstrated. Depending on availability of leveraging funding sources, microbial monitoring techniques for both airborne and waterborne loads may be demonstrated. Areas of technical emphasis for environmental monitoring are the following:

1) Vehicle Environmental Monitor (VEM) to expand GC/MS technology used for cabin atmosphere analysis to address water analysis.

2) Micro-Gas Monitor (mGM) to achieve major size reduction to GC/MS without loss of capability.

3) Tunable Laser Absorption (TELS) to apply solid state laser developments to targeted gas analytes.

4) Rapid Analysis Self-Calibrating (RASCal) Array to apply advanced array analysis and hardware to dramatically improve response time and calibration time.

5) Microbiological Monitors for water-borne and air-borne analysis.

All developmental tasks are unified by a Performance testing to characterize targeted LSS process technology, validate process technology models, and simulate technical product performance on board the ISS and application to deep space exploration vehicles and habitats will be conducted. The testing and validation will occur at varying 
degrees of complexity starting at the component level up to the fully integrated subsystem level. The ARREM Project testing objectives are the following:

1) To assess the feasibility of canidiate improvements to the SOA LSS and their operational concepts.

2) To advance, demonstrate and integrate LSS technologies that enable future space exploration activities

3) To develop long-range, critical LSS technologies to provide the foundation for a broad set of future exploration capabilities.

4) To provide an infusion path for promising, game-changing LSS technologies.

The ARREM Project will systematically and carefully evaluate technologies at specific points of their development to determine the right approach for maturity using a stage-gate methodology. ${ }^{4}$ Sub-scale and/or full scale equipment may be employed as appropriate as maturity progresses. Test articles will more closely approach the specified maturity goals in function, fit, and form as the technology advances through the maturation stages. Varying degrees of integration are employed at each maturity level. Before promoting a technology from one maturity stage to another, the effort is reviewed at each stage gate to determine if progress toward completing specific technical content is sufficient. Based on results of the stage assessment, a decision is made to promote the process technology to the next maturity level, retain it at its present level, place the development on hold, demote to a lower level, or terminate the effort. Once a technology development maturity level of TRL 5 has been demonstrated, the product is ready for infusion into a flight project development effort for further maturity (through the TRL 9 level) into flight hardware and usage as a flight validated technology application.

\section{Complementary Project and Program Relationships}

Collaboration and synergy within NASA and the LSS community is necessary an imparative to maintaining a long-term human presence in space beyond LEO. The ARREM project consists of six participating NASA field center that bring targeted expertise to the project. The participating field centers are the following:

1) Marshall Space Flight Center-project management, $\mathrm{CO}_{2}$ removal, trace contaminant control, resource recovery, and integrated testing.

2) Jet Propulsion Laboratory-provides environmental monitor and instrumentation development.

3) Johnson Space Center-open-loop $\mathrm{CO}_{2}$ removal, gas compression, and gas conditioning.

4) Ames Research Center-gas drying and solid state $\mathrm{CO}_{2}$ compression.

5) Kennedy Space Center-adsorbent and catalyst characterization.

6) Glenn Research Center-particulate filtration and disposal technology.

The ARREM project has technical and programmatic relationships outlined by Fig. 6 with multiple NASA field centers as well as other research and technology programs and projects which are complementary and integral to developing operational capabilities for exploration missions of the future. These complementary project ts include projects investigating technologies for water processing and logistics reduction. Some logistics reduction equipment may produce concentrated chemical chemical waste streams that the ARS or ARS-derived

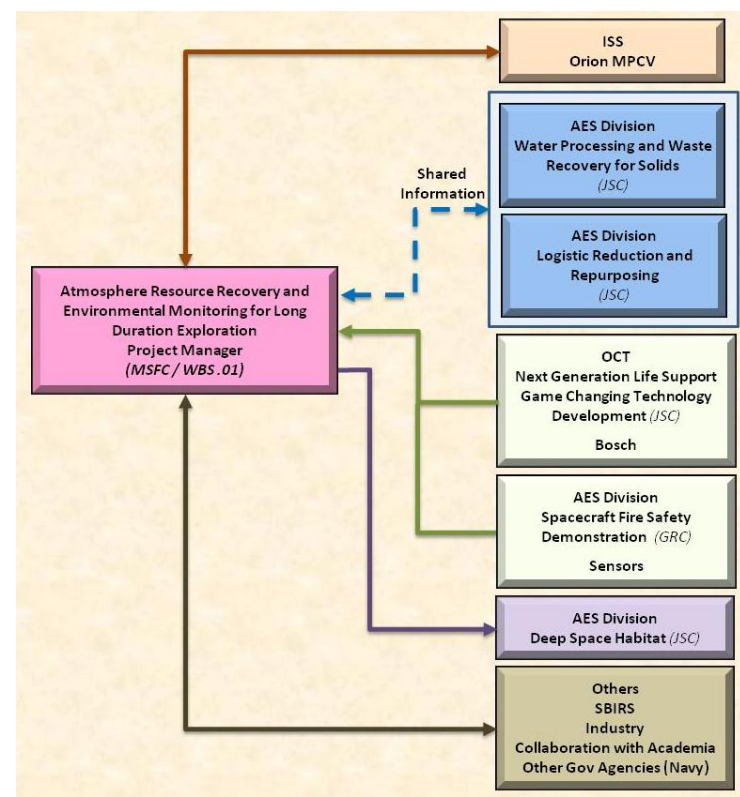

Figure 6. The ARREM Project relationships with complementary research and technology efforts.

technologies must process making technical interchange between the projects highly advantageous. Water processing equipment could potentially be processing the water produced by the $\mathrm{CO}_{2}$ reduction system and the OGA will use product water for the electrolysis process. In addition, the ARREM Project will work with the habitat design projects to ensure the latest mission requirements are considered and to coordinate the incorporation of ARREM products into habitat design architectures.

\section{Conclusion}

The ARREM project is supported by an experienced, multi-disciplinary team focused on assessing, maturing, and testing ARS and EMS technologies to improve reliability, maximize commonality, and reduce resource 
demands. The project will mature the optimum ARS and EMS architecture and subsystem configurations to address the demands of a broad spectrum of crewed space exploration mission objectives. The project will select and functionally demonstrate test articles for each of the ARS and EMS functional areas. Further development toward achieving flight-like maturity will be conducted as resources can afford. Higher fidelity equipment development will emphasize those components and assemblies that are expected to have the greatest impact on overall LSS reliability. These upgraded test articles will be dedicated to extended duration testing to demonstrate performance robustness and functional endurance over a wide range of loads and environmental conditions selected to encompass anticipated nominal and off-nominal exploration conditions. Once performance and edurance testing is completed, a high fidelity subsystem consisting of each function will be available for integration and operation in a higher-level integrated test to demonstrate performance in tandem with other ECLSS functions under nominal operational mission conditions.

\section{References}

${ }^{1}$ Perry, J. L., Bagdigian, R. M., and Carrasquillo, R. L. "Trade Spaces in Crewed Spacecraft Atmosphere Revitalization System Development," AIAA 2010-6061, 40 ${ }^{\text {th }}$ International Conference on Environmental Systems, Barcelona, Spain, 2010.

${ }^{2}$ Perry, J. L., Abney, M. B., Knox, J. C., Parrish, K. J., Roman, M.C., Jan, D. L., "Integrated Atmosphere Resource Recovery and Environmental Monitoring Technology Demonstration for Deep Space Exploration," AIAA 2012-3585, 42 ${ }^{\text {nd }}$ International Conference on Environmental Systems, San Diego, California, 2012.

${ }^{3}$ Jan, D. L., and Newton, R., " Environmental Monitoring as a part of Life Support: Deep Space Exploration," AIAA 20123433, 42 ${ }^{\text {nd }}$ International Conference on Environmental Systems, San Diego, California, 2012.

${ }^{4}$ Perry, J.L. and Howard, D.F. (2007) "Spacecraft Life Support System Process Technology Maturation using Stage Gate Methodology," SAE 2007-01-3045, 37 International Conference on Environmental Systems, Chicago, Illinois, 2007. 


\title{
Design, Development, Test,
}

\section{and Evaluation of Atmosphere Revitalization and Environmental Monitoring Systems for Long Duration Missions}

\author{
Presentation for \\ AIAA Space 2012 \\ Conference \& Exposition \\ September 11 - 13, 2012
}

Monsi Roman/Project Manager NASA, Marshall Space Flight Center 


\section{ARREM Project Objectives}

The objectives and goals of the Atmosphere Revitalization Systems (ARS) and Environmental Monitoring Systems (EMS) technology maturation tasks within the ARREM Project include:

- Assess existing Atmosphere Revitalization Systems (ARS) and Environmental Monitoring Systems (EMS) candidates that offer the greatest potential to maximize system commonality across a variety of mission scenarios and vehicle concepts anticipated in a flexible exploration framework.

- Advance the technical maturity as measured by the Technology Readiness Level (TRL) of candidate technologies for flexible ARS architectures spanning the range of exploration mission objectives and vehicle concepts thus providing risk reduction and developmental economy to flight project development programs.

- Develop a set of resource recovery capabilities that can be added in modular "plug-n-play" fashion to a common set of core, modular ARREM equipment to allow mission planners flexibility to extend crewed mission durations without compromising core equipment functionality.

- Demonstrate the evolution of the International Space Station (ISS) state-of-the-art (SOA) ARS/EMS baseline via targeted advancements that benefit ISS operations in Low Earth Orbit (LEO) and exploration missions beyond Earth orbit. Benefits include improved operational margins and reliability, reduced technical risk, and lower lifecycle cost.

Multi-Center team focused on assessing, maturing and testing ARS/EMS technologies to: improve reliability, maximize commonality, and reduce resources (consumables, mass, volume, power, etc) 


\section{ARREM Project Management Structure}

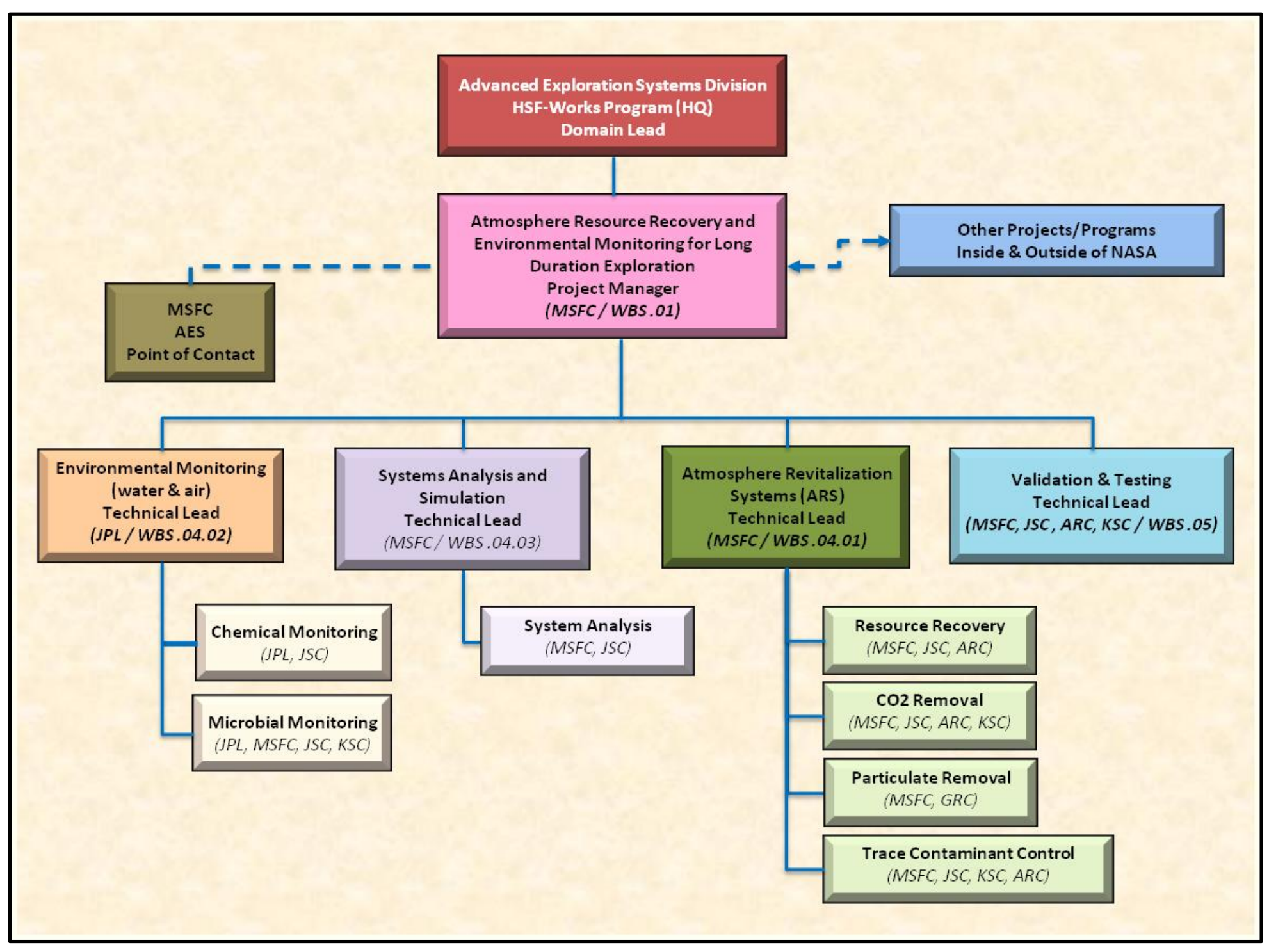




\section{ARREM Project Team}

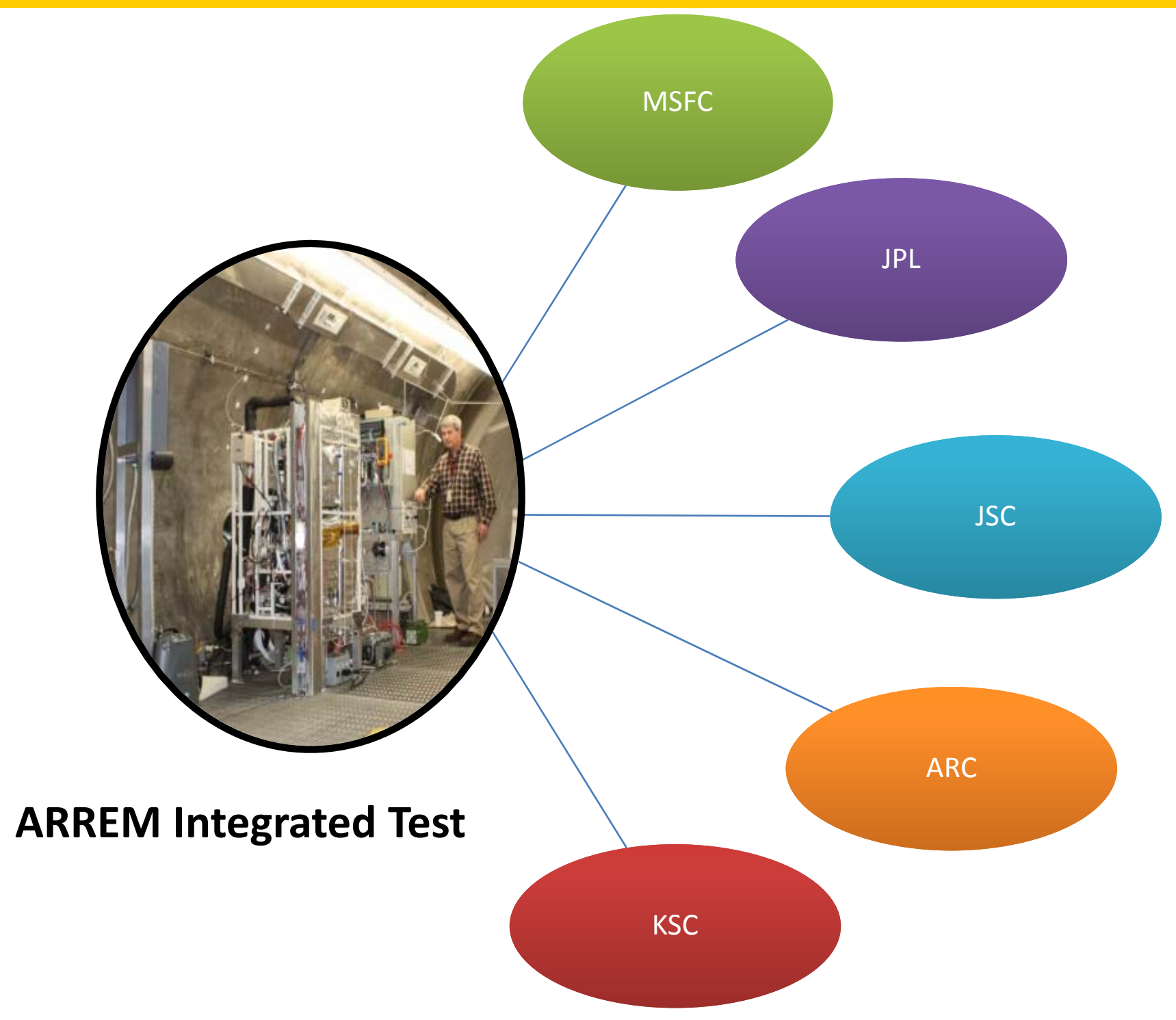




\section{ARREM Innovative Approaches}

Baselined ARS and EMS architecture, that could be used in a DSH ECLSS integrated test, by the end of FY14
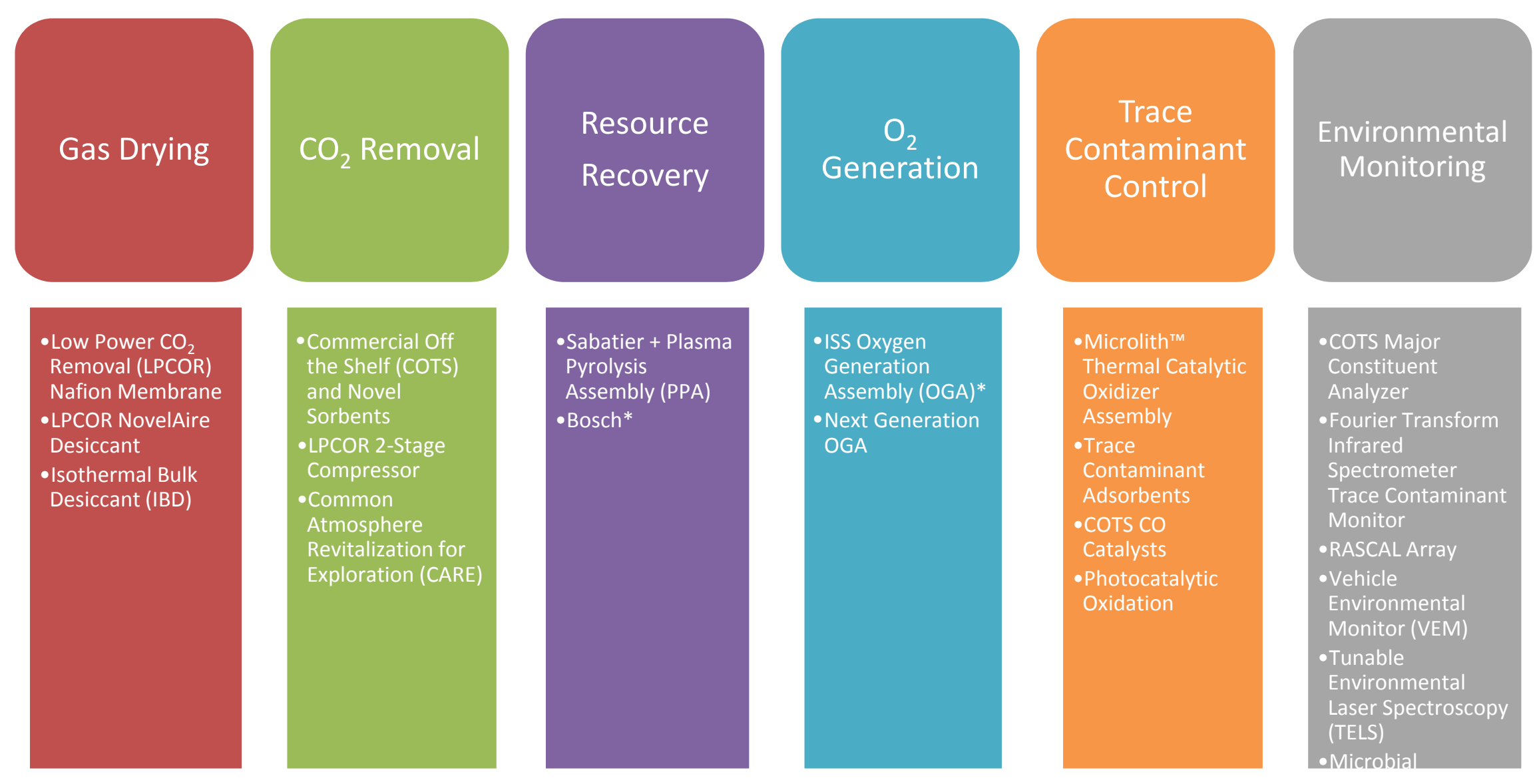

* Not funded by AES 


\section{ARREM Project Functions}






\section{ARREM Project Approach}

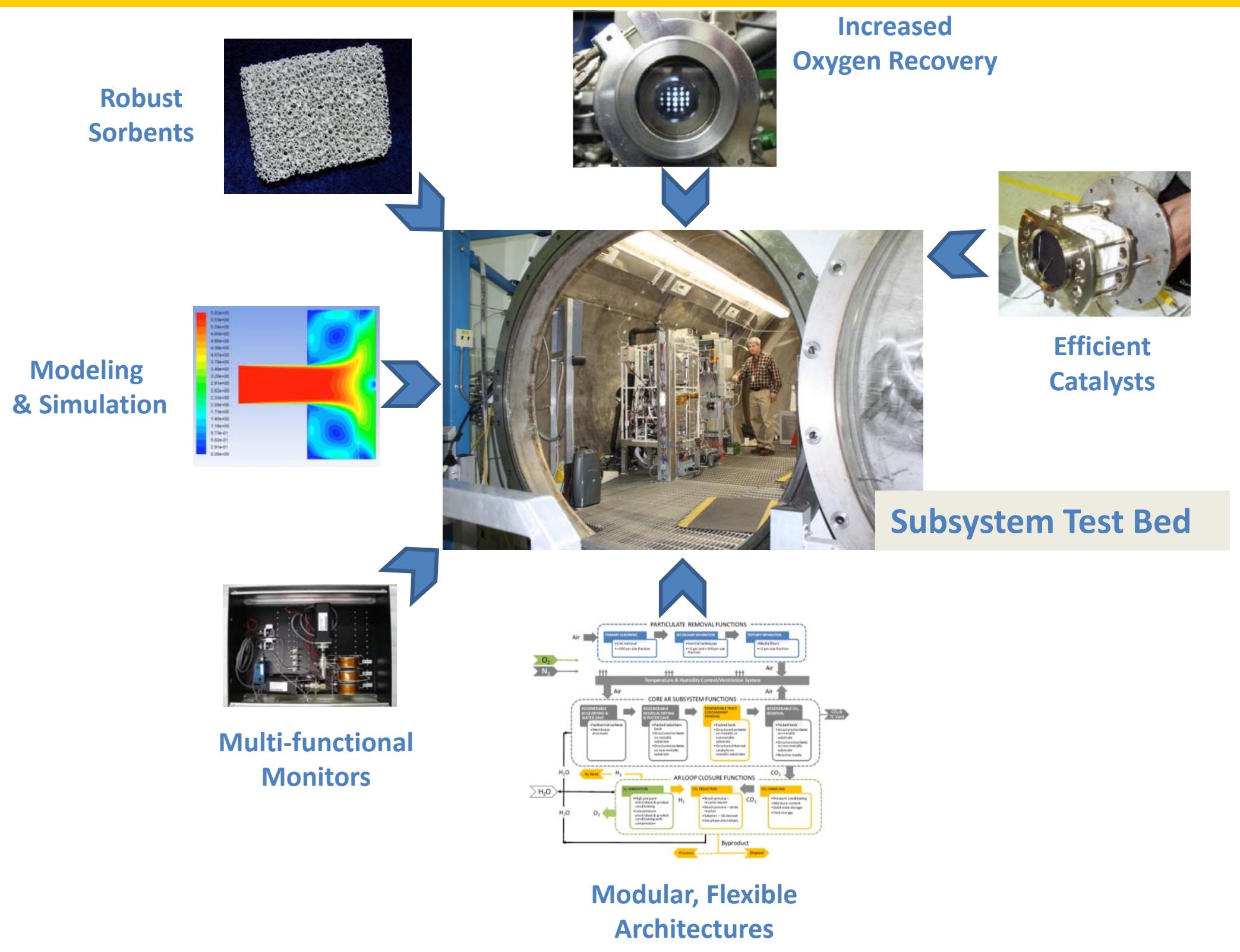




\section{ARREM Project Accomplishments}

$>$ Major Accomplishments To Date

- Work Plan Completed and Signed by HQ's

- Technical Task Agreements Completed and in Signature Cycle

- Integrated Master Schedule Completed and in Final Review

- Started baseline ground test of integrated ISS AR/EM systems test in preparation for the ARREM Cycle 1 integrated test.

- UMPQUA Research Co. delivered 2nd generation PPA 1 crew member reactor; it was installed and successfully operated.

- The LPCOR adsorbent containment system has been designed and the canister rack design has started.

- Abstracts submitted for the 42nd ICES

- ARREM budget planning for FY13-14

- AES DSH Phase II Whitepaper completed

\section{Team continues the maturation of ARS candidate hardware (bench testing) for potential integration in Cycle 1, 2 and/or 3}




\section{ARREM Project Accomplishments (cont'd)}

\section{$>$ Major Accomplishments To Date}

- VEM: Constructed liquid water sampling module, in process of testing and optimizing.

- mGM: Received Cbana PreConcentrator test article, working integration to mass spectrometer.

- TELS: Fabricated preliminary solid lasers for CO spectroscopy.

- RASCal: Started taking data on preliminary analytes, will contract with UCSD for algorithm development; received and testing SBIR major constituent analyzer from Innosense.

- Support of OCT GCD Microbial Monitoring Formulation.

Team continues the maturation of EMS candidate hardware (bench testing) for potential integration in Cycle 2 and/or 3
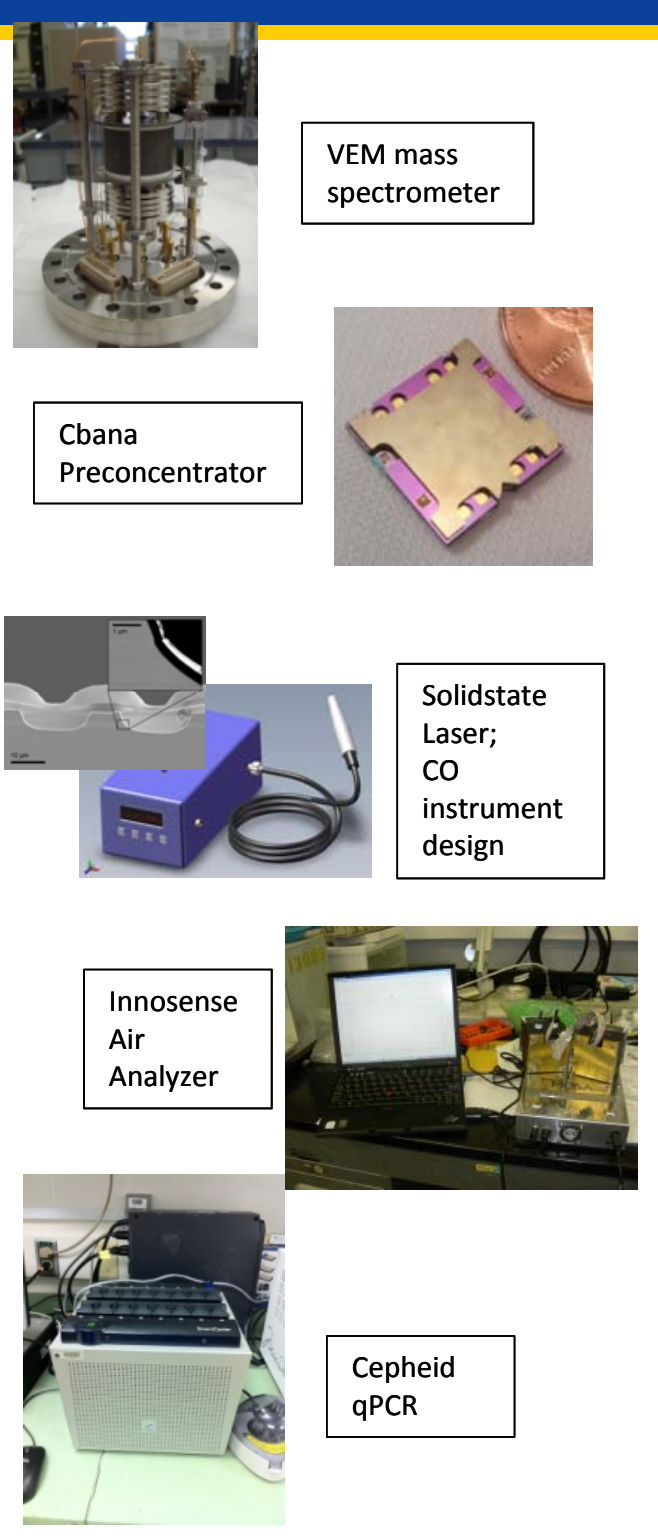

Cepheid qPCR 


\section{ARREM Project Accomplishments}

\section{> Major Accomplishments To Date (Project Management)}

- TIM with NAVSEA/NASA CO2 removal team @ HQ. MSFC invited to participate in the NAVSEA CDR for their CO2 removal system. Will continue analysis of their amine bead.

- Working possibilities to help ISS project build new CDRA-4 prototype

- Participated in review of NASA's funded ISS traveling exhibit blue prints with Science Museum of Minnesota

- Participated in the Hostos College STEM activity (NASA Day)

- Completed Space Act Agreement with Hamilton Sundstrand (CO2 Compressor). Working on the procurement for refurbishment

- Developed AES Phase 1 ARREM requirements and sent to HQ

- Provided inputs to HQ's for Habitation Domain APG

- Working with MSFC NASA TV team to develop a life support App

- Worked with NASA's education website Associate Editor for Do-It-Yourself Podcast

- ARREM Project collaborated with the ISS ECLSS team to build test articles and test improvements

- Review of ECLSS schematics for Deep Space Habitation mission

- Interviewed for the Marshall Star and TW@N (Silver Telly Award)

- Discussions were held with ISS office (FP) to coordinate funding and future testing needs for ARREM/ISS co-funded hardware (CDRA and OGA)

- Working with NASA HQ in an AES collaboration matrix (all habitation projects) and concept operation(ConOps) plan

- Attended 42 ${ }^{\text {nd }}$ ICES. Session Organizer/Chair. 11 papers presented for ARREM Project.

- Video of ARREM testing facilities for AES Program office 


\section{ARREM Project Milestone Summary}

\begin{tabular}{|c|l|c|c|}
\hline Item & \multicolumn{1}{|c|}{ FY12 Major Milestones } & Date & Status \\
\hline 1 & $\begin{array}{l}\text { Begin testing of breadboard system to recycle recovered } \\
\text { hydrogen (H2) in the Carbon Dioxide Reduction systems }\end{array}$ & $6 / 30 / 2012$ \\
\hline 2 & $\begin{array}{l}\text { Start Cycle 1 integrated chamber testing of the Atmosphere } \\
\text { Revitalization Systems (ARS) and the Environmental Monitoring } \\
\text { Systems (EMS) }\end{array}$ & $8 / 1 / 2012$ & Completed \\
\hline 3 & $\begin{array}{l}\text { Begin test of 1-crew member sized Plasma Pyrolysis Assembly to } \\
\text { recover hydrogen (H2) from methane (CH4) }\end{array}$ & $9 / 30 / 2012$ & \\
\hline
\end{tabular}




\section{ARREM Project Milestones \#1}

Milestone: Begin testing of breadboard system (Acetylene Separation Assembly/ ASepA) to recycle recovered hydrogen (H2) in the Carbon Dioxide Reduction Systems

\section{Due Date: COMPLETED}

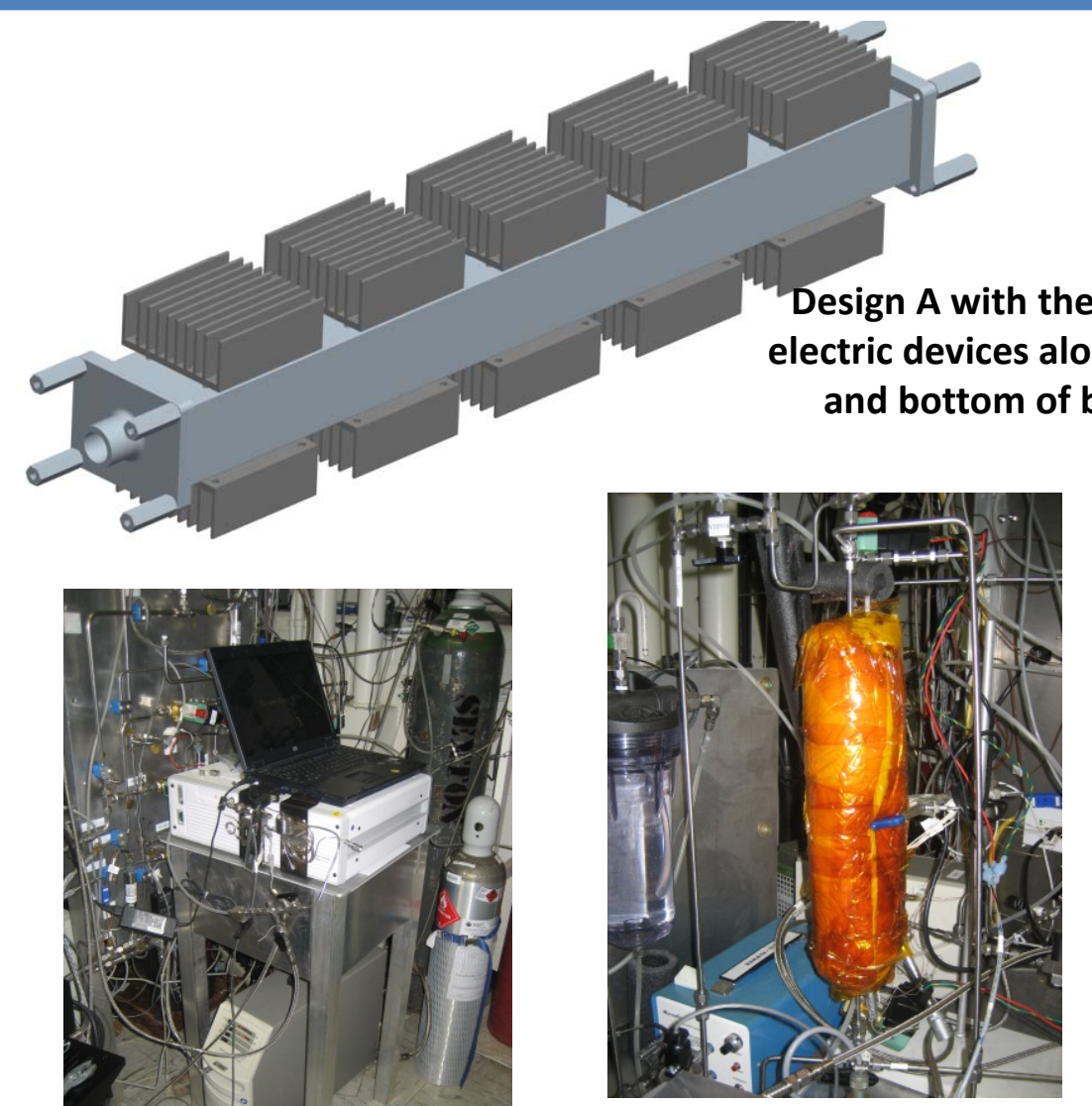

Sub-scale bed used to facilitate design effort

Gas Analysis Systems for monitoring breadboard testing

- Design (85\% Complete)

- Design A involves the use of thermo-electric devices for heating and cooling the bed

- Pro: Maximizes thermal efficiency

- Con: Limits bed regeneration temperature to $<200^{\circ} \mathrm{C}$

- Design $B$ involves the use of thermo-electric devices for cooling the bed and traditional heaters for heating the bed

- Pro: No contraining limits on regeneration temperature

- Con: Multiple devices necessary for heating and cooling

- Analysis (75\% Complete)

- Preliminary explosion analysis completed

- Design-specific explosion analysis ongoing

- Performance modeling ongoing

- Fabrication (Not started)

- Testing (25\% Complete)

- Test stand modifications complete

- Gas analysis systems installed and operational

- Sub-scale testing ongoing to facilitate design efforts

ASepA is an in-house zeolite-based design that will capture acetylene and allows hydrogen and methane to be recycled back to the PPA 


\section{ARREM Project Milestones \#3}

Milestone: Begin test of 1-crew member (1-CM) sized Plasma Pyrolysis Assembly (PPA) to recover hydrogen $(\mathrm{H} 2)$ from methane $(\mathrm{CH} 4)$.

Result in a full-scale prototype (crew of 4) by FY14.

\section{Due Date: COMPLETED}

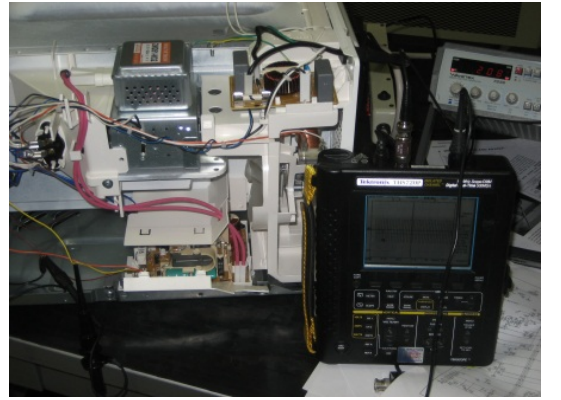

Power Supply Modifications and Testing



2nd Generation PPA Reactor (1-CM size)

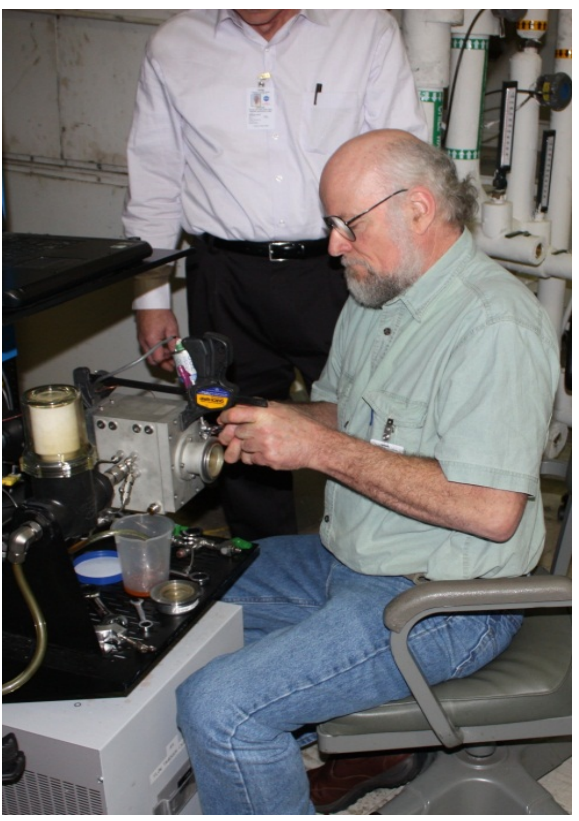

Engineer from UMPQUA Research Company assists in installation and initial check-out of 1-CM PPA reactor
- Hardware (100\% Complete)

- $2^{\text {nd }}$ Generation PPA reactor delivered to MSFC in late January

- Reactor installed into the test stand in early February

- Test Stand Modifications (60\% Complete)

- Procurements pending for test stand updates necessary for operation of a 1-CM sized system

- Improved power supply undergoing modifications for installation into test stand

- Testing (5\% Complete)

- Initial check-outs of the reactor completed to confirm cooling loop, flow paths, and plasma ignition at sub-scale operational parameters
The reactor will efficiently recover hydrogen from methane produced by the Carbon Dioxide Reduction Assembly (CRA)/ Sabatier 


\section{ARREM Project Milestones \#2}

Milestone: Start Cycle 1 integrated chamber testing of the Atmosphere Revitalization Systems (ARS) and the Environmental Monitoring System (EMS).

Due Date: COMPLETED

ISS ARS SOA hardware installed and integrated in the test chamber; baseline testing started

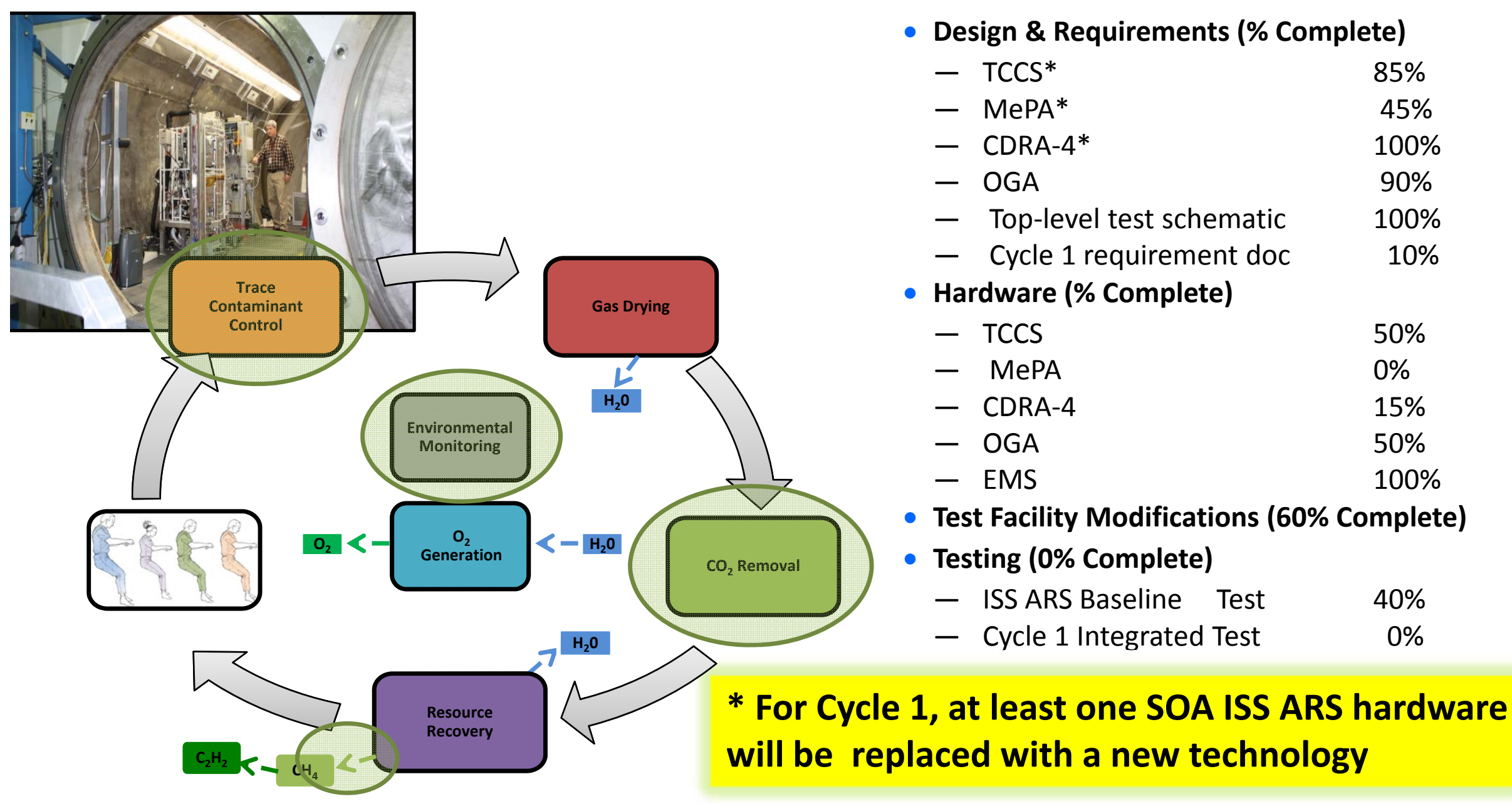




\section{ARREM Project Plans}

\section{$>$ Plans for FY12}

- Technology Interchange Meeting with COMNAVSEA Undersea Technology Office

- Complete SAA with Hamilton Sundstrand to acquire ISS CO2 compressor

- Complete baseline ground test of integrated ISS AR/EM Systems

- Begin test of Acetylene Separation Assembly

- Begin test of 1-crew member sized PPA reactor

- Finalize ARREM Customer Support Agreement

- Close action from Chris Moore on ECLSS Testing Facilities (JSC and MSFC)

- Support 42nd ICES Conference

- Continue planning for Cycle 2 and 3 integrated chamber test

\section{Start ARREM Cycle 1 integrated test}




\section{ARREM Project Plans}

\section{$>$ Major Milestones Planned for FY13 (Draft)}

\begin{tabular}{|c|l|c|}
\hline Item & \multicolumn{1}{|c|}{ FY13 Milestones } & Date \\
\hline 1 & $\begin{array}{l}\text { Downselect core AR process technologies for Cycle 2 architecture } \\
\text { (advanced pelletized CO2 sorbent, bulk drying, and residual drying) - } \\
\text { (note: the CO2 pelletized sorbent and bulk/residual drying downselects } \\
\text { all have the same date on the schedule) }\end{array}$ & $\mathbf{2 / 2 0 1 3}$ \\
\hline 2 & $\begin{array}{l}\text { Start the Process of Remotely Connecting the Atmosphere Resource } \\
\text { Recovery and Environmental Monitoring (ARREM) Subsystem Integrated } \\
\text { Test to the Deep Space Habitation (DSH) System Test. }\end{array}$ & $4 / 2013$ \\
\hline 3 & $\begin{array}{l}\text { Complete Oxygen Generation Assembly (OGA) system improvement } \\
\text { analyses and component testing plans needed for the design of the 2nd } \\
\text { generation OGA. }\end{array}$ & $6 / 2013$ \\
\hline 4 & $\begin{array}{l}\text { Start Cycle 2 integrated chamber testing of the Atmosphere } \\
\text { Revitalization Systems (ARS) and the Environmental Monitoring } \\
\text { Systems (EMS) }\end{array}$ & $\mathbf{8 / 2 0 1 3}$ \\
\hline
\end{tabular}




\section{ARREM Project Interactions}

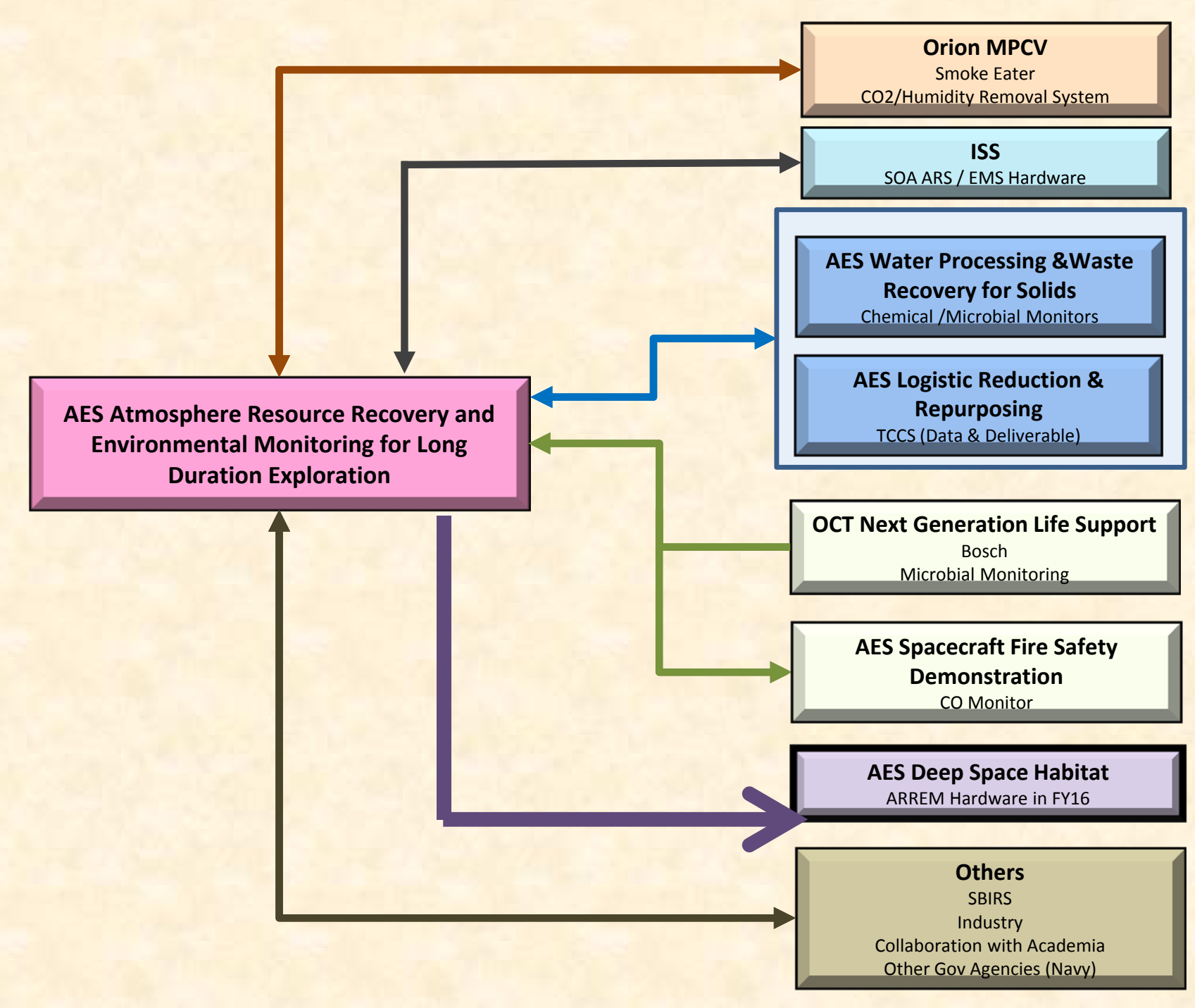


ARREM Innovative

Approaches

for

Project Execution 


\section{ARREM Innovative Approaches}

\section{Use of existing test facilities}

Integrated testing at $14.7 / 21 \% \mathrm{O} 2,10.2 / 30 \%$ O2 or 8 psia/32\% O2

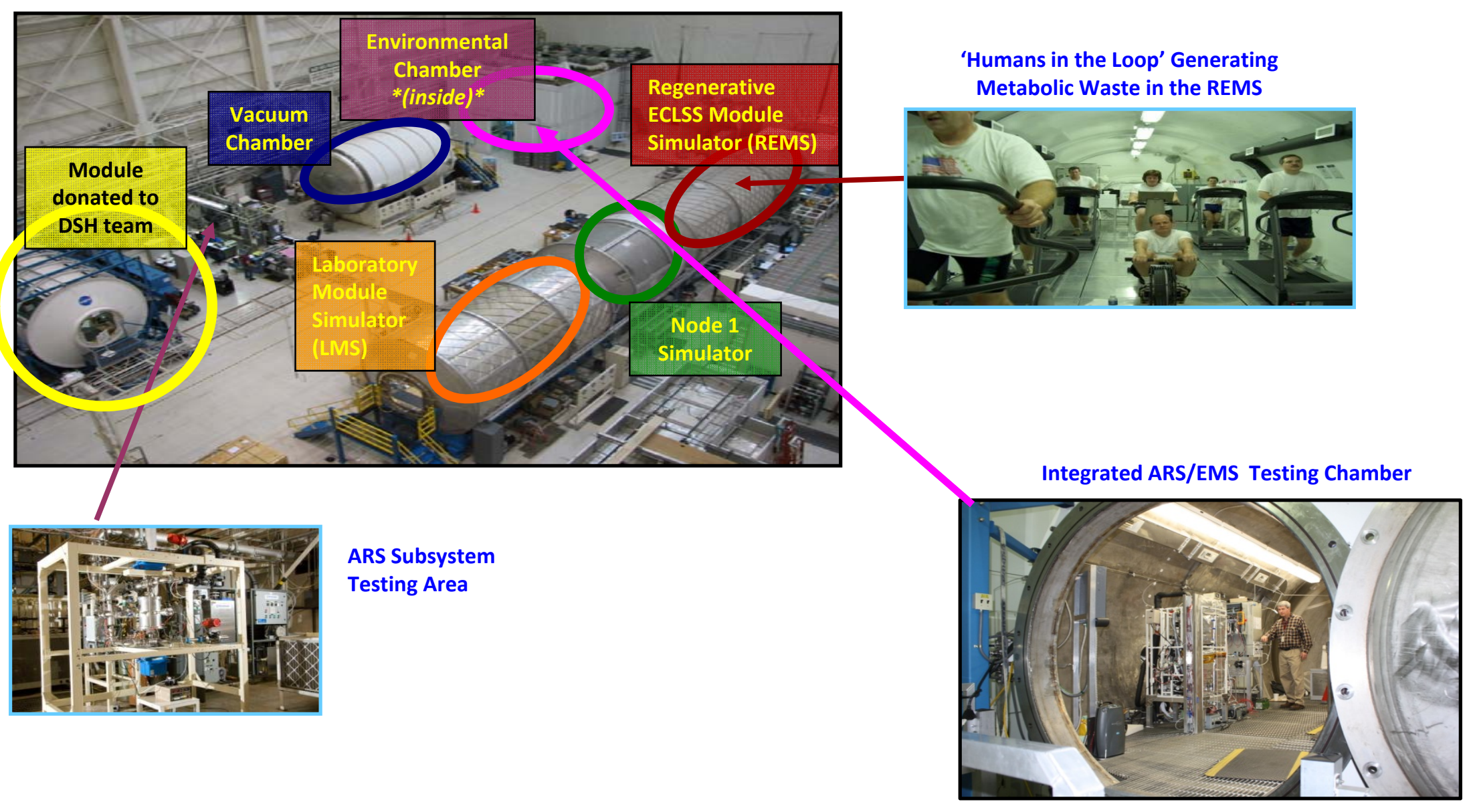




\section{ARREM Innovative Approaches}

Provide the Agency with a short- and long-term plan for the assessment and testing of ARS and EMS technologies (stand-alone and integrated) that can be used in short- and long-duration missions.



\section{ARREM Innovative Approaches}

Perform integrated testing that incorporates new or improved ISS technologies with existing ISS ARS test hardware






\section{ARREM Innovative Approaches}

Work with other AES projects to share funds; leveraging on other funding sources like SBIRs, OCT, Center innovative funds






\section{Back Up}




\section{ARREM Task Description}

\section{Carbon Dioxide Removal}

- SOA: ISS carbon dioxide removal assembly (CDRA)

$-\mathrm{CO}_{2}$ sorbents to improve reliability

- Open loop $\mathrm{CO}_{2}$ removal concepts that use either immobilized amine or mixed zeolite sorbents that can potentially replace the $\mathrm{CO}_{2}$ removal beds in a CDRA-like process

- Energy-efficient structured sorbents and other alternative sorbents as well as membrane

- Cabin and ventilation system interface issues, including interface issues with a vehicle suit loop will be investigated.

\section{Oxygen Recovery}

- Oxygen generation SOA: ISS oxygen generation assembly (OGA)

- Investigate robust, reliable water electrolysis cell stack that addresses issues

- Oxygen drying and compression options, both temperature swing adsorption-based and mechanical compressor-based, will be considered.

\section{- CO2 Reduction SOA: None}

- Plasma methane pyrolysis, the leading methods for recovering additional hydrogen from ISS Sabatier process waste methane will be evaluated.

- Methods for handling hydrogen within the OGA-Sabatier-methane post-processing string will be investigated.

\section{Trace Contaminant Control}

- SOA: ISS Trace Contaminant Control (TCC) System

- Assess adsorbent media and catalysts; best will be applied to an ISS-derived TCC

- Integration of TCC equipment with CO2 removal

- Development of photocatalytic oxidation processes to niche applications that reduce volatile organic loading in humidity condensate will be conducted to alleviate the logistics penalty associated with this phenomenon as observed aboard the ISS.

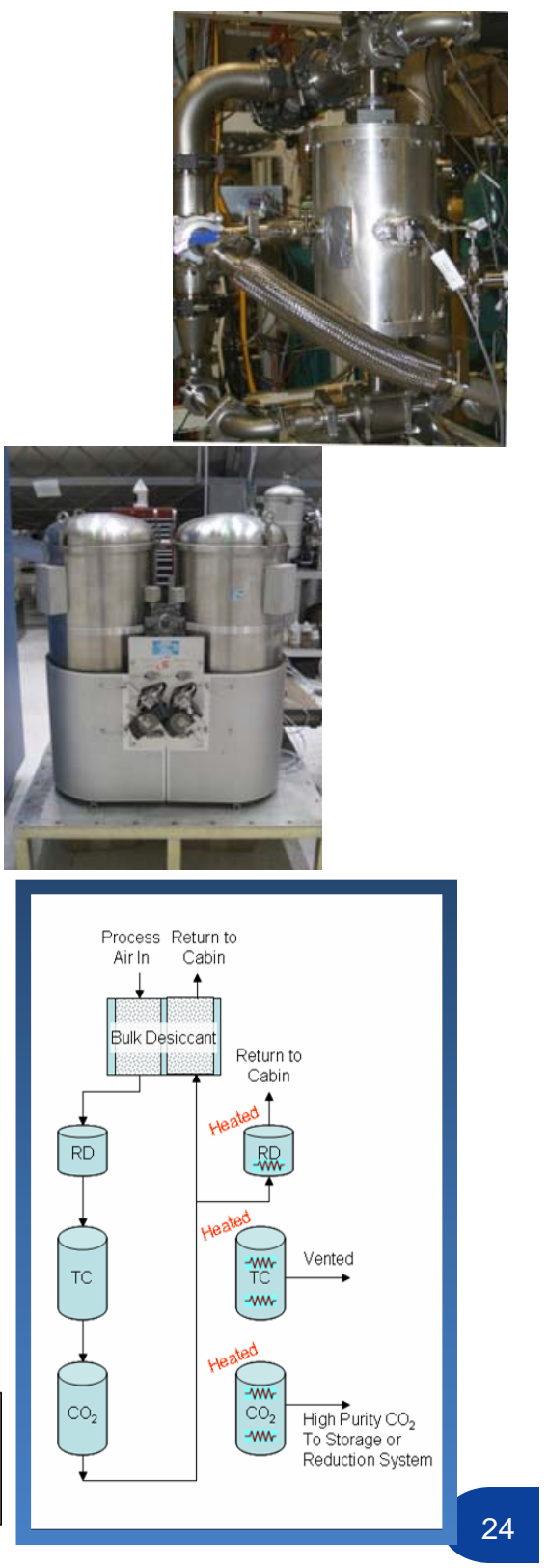




\section{ARREM Task Description (cont'd)}

\section{Environmental Monitoring}

- The best performing atmospheric monitoring candidates demonstrated on board the ISS to date will be operated in tandem to determine the best suite of instruments necessary to provide vehicle operational autonomy necessary for deep exploration missions. Monitoring instrument recommendations will be submitted to the ISS Program to improve functional autonomy and reduce reliance on assessing cabin air quality using grab samples that rely on ground analysis and logistics between Earth and orbit. Early warning instruments targeting specific analytical targets will be demonstrated. Extending air quality instrument function to include front-end processors to allow for volatile organic monitoring in potable water will be demonstrated.

- Microbial monitoring techniques for both airborne and waterborne loads will be demonstrated.

\section{Systems Analysis \& Simulation}

- ECLS System architectures, process technology models, and functional trade assessments will be conducted to support and refine the test and evaluation activities through the duration of the project.

\section{Validation and Testing}

- Performance testing to characterize targeted ECLS system process technology, validate process technology models, and simulate technical product performance on board the ISS and application to deep space exploration vehicles and habitats will be conducted. The testing and validation will occur at varying degrees of complexity starting at the component level up to the fully integrated subsystem level. 


\section{ARREM Product Summary}

\section{Chamber}

\begin{tabular}{|c|c|c|c|c|}
\hline \multirow{6}{*}{$\begin{array}{l}\text { In the } \\
\text { Chamber }\end{array}$} & WBS & 2012 & 2013 & 2014 \\
\hline & $\mathrm{CO}_{2}$ Removal & $\begin{array}{l}\text { - ISS CDRA-4 (Developmental unit } \\
\text { packed with CDRA-4 flight } \\
\text { sorbents) }\end{array}$ & $\begin{array}{l}\text { - Bulk Desiccant: Membrane or } \\
\text { isothermal bulk desiccant } \\
\text { - Residual Desiccant: NovelAire or } \\
\text { H2O Microlith } \\
\text { - } \text { CO2 Removal: CDRA-4 flight } \\
\text { sorbents or alternative sorbent }\end{array}$ & $\begin{array}{l}\text { - Bulk Desiccant: Same as Cycle } 2 \\
\text { - Residual Desiccant: Same as Cycle } 2 \\
\text { - CO2 Removal: 2-Stage compressor or } \\
\text { CO2 Microlith or Common } \\
\text { Atmosphere Revitalization (CARE) }\end{array}$ \\
\hline & Resource Recovery & $\begin{array}{l}\text { - Sabatier with Methane Purification } \\
\text { Assembly (MePA) } \\
\text { - ISS piston compressor with CO2 } \\
\text { accumulator } \\
\text { - ISS Oxygen Generator Assembly } \\
\text { (OGA) }\end{array}$ & $\begin{array}{l}\text { - Sabatier with MePA } \\
\text { - Sub-scale Plasma Pyroysis Assembly } \\
\text { (PPA) } \\
\text { - Acetylene Separation Assembly } \\
\text { (ASepA) } \\
\text { - ISS piston compressor with } \mathrm{CO} 2 \\
\text { - } \text { accumulator } \\
\text { - ISS OGA } \\
\text { O2 compression }\end{array}$ & $\begin{array}{l}\text { - Sabatier } \\
\text { - MePA } \\
\text { - Full-Scale PPA } \\
\text { - Full-scale ASepA } \\
\text { - Microlith Sabatier } \\
\text { - O2 compression }\end{array}$ \\
\hline & TCCS & $\begin{array}{l}\text { - Microlith high temperature } \\
\text { catalytic oxidizer (HTCO) unit (>30 } \\
\text { day mission) } \\
\text { - Layered bed containing } \\
\text { Chemsorb } 1425 \text { \& Carulite } 300 \\
\text { (30-day mission TCC unit) } \\
\text { - Fixed sorbent bed containing } \\
\text { Chemosorb } 1425 \text { (>30 day } \\
\text { mission) }\end{array}$ & $\begin{array}{l}\text { - Microlith HTCO unit } \\
\text { - Optimized fixed sorbent bed } \\
\text { containing Chemsorb media } \\
\text { - Optimized layered bed containing } \\
\text { VOC sorbent and ambient } \\
\text { temperature catalyst }\end{array}$ & $\begin{array}{l}\text { - Microlith HTCO unit } \\
\text { - Final design fixed sorbent bed } \\
\text { - Final design layered VOC } \\
\text { sorbent/ambient temperature } \\
\text { catalyst bed } \\
\text { - Combustion product removal device } \\
\text { - Ammonia catalytic reduction } \\
\text { augmentation (based on downselect) } \\
\text { - Photocatalytic oxidation } \\
\text { augmentation (based on } \\
\text { downselect) } \\
\end{array}$ \\
\hline & Particulate Removal & $\begin{array}{l}\text { - Commercial high-efficiency media } \\
\text { filter }\end{array}$ & $\begin{array}{l}\text { - Commercial high-efficiency media } \\
\text { filter }\end{array}$ & $\begin{array}{l}\text { - Indexing media filter with inertial } \\
\text { separator }\end{array}$ \\
\hline & $\begin{array}{c}\text { Environmental } \\
\text { Monitoring }\end{array}$ & $\begin{array}{l}\text { - First-round COTS Major } \\
\text { Constituent Analyzer (MCA) }\end{array}$ & $\begin{array}{l}\text { - Second-round COTS MCA } \\
\text { - COTS VOC analyzer }\end{array}$ & $\begin{array}{l}\text { - Third-round COTS MCA } \\
\text { - VEM/mGM/TELS/RASCaL array }\end{array}$ \\
\hline
\end{tabular}




\section{ARREM Product Summary}



